\title{
2010s-06
}

\section{Competitive Private Supply of Public Goods}

\author{
Arnaud Z. Dragicevic, Guy Meunier
}

\begin{tabular}{c}
\hline Série Scientifique \\
Scientific Series
\end{tabular}

\section{Montréal \\ Janvier 2010}

(C) 2010 Arnaud Z. Dragicevic, Guy Meunier. Tous droits réservés. All rights reserved. Reproduction partielle permise avec citation du document source, incluant la notice (C).

Short sections may be quoted without explicit permission, if full credit, including (C) notice, is given to the source.
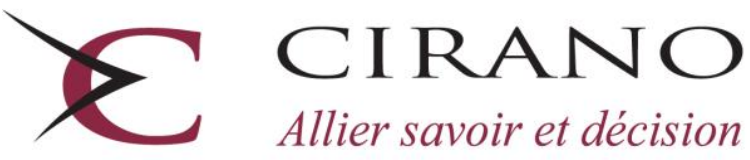

Allier savoir et décision

Centre interuniversitaire de recherche en analyse des organisations 


\section{CIRANO}

Le CIRANO est un organisme sans but lucratif constitué en vertu de la Loi des compagnies du Québec. Le financement de son infrastructure et de ses activités de recherche provient des cotisations de ses organisations-membres, d'une subvention d'infrastructure du Ministère du Développement économique et régional et de la Recherche, de même que des subventions et mandats obtenus par ses équipes de recherche.

CIRANO is a private non-profit organization incorporated under the Québec Companies Act. Its infrastructure and research activities are funded through fees paid by member organizations, an infrastructure grant from the Ministère du Développement économique et régional et de la Recherche, and grants and research mandates obtained by its research teams.

\section{Les partenaires du CIRANO}

Partenaire majeur

Ministère du Développement économique, de l'Innovation et de l'Exportation

\section{Partenaires corporatifs}

Banque de développement du Canada

Banque du Canada

Banque Laurentienne du Canada

Banque Nationale du Canada

Banque Royale du Canada

Banque Scotia

Bell Canada

BMO Groupe financier

Caisse de dépôt et placement du Québec

Fédération des caisses Desjardins du Québec

Financière Sun Life, Québec

Gaz Métro

Hydro-Québec

Industrie Canada

Investissements PSP

Ministère des Finances du Québec

Power Corporation du Canada

Raymond Chabot Grant Thornton

Rio Tinto

State Street Global Advisors

Transat A.T.

Ville de Montréal

\section{Partenaires universitaires}

École Polytechnique de Montréal

HEC Montréal

McGill University

Université Concordia

Université de Montréal

Université de Sherbrooke

Université du Québec

Université du Québec à Montréal

Université Laval

Le CIRANO collabore avec de nombreux centres et chaires de recherche universitaires dont on peut consulter la liste sur son site web.

Les cahiers de la série scientifique (CS) visent à rendre accessibles des résultats de recherche effectuée au CIRANO afin de susciter échanges et commentaires. Ces cahiers sont écrits dans le style des publications scientifiques. Les idées et les opinions émises sont sous l'unique responsabilité des auteurs et ne représentent pas nécessairement les positions du CIRANO ou de ses partenaires.

This paper presents research carried out at CIRANO and aims at encouraging discussion and comment. The observations and viewpoints expressed are the sole responsibility of the authors. They do not necessarily represent positions of CIRANO or its partners. 


\title{
Competitive Private Supply of Public Goods
}

\author{
Arnaud Z. Dragicevic", Guy Meunier ${ }^{+}$
}

\begin{abstract}
Résumé / Abstract
Le papier fait la comparaison entre déculpabilisation et compétition pour le statut social dans la provision privée des biens publics. Lorsque les agents sont intrinsèquement impulsés, c'està-dire qu'ils contribuent essentiellement aux biens publics dans le but de soulager leur culpabilité d'avoir indirectement participé à leur dégradation, ils tendent à se comporter en passagers clandestins. En revanche, lorsque les agents sont extrinsèquement impulsés et se mettent en compétition pour atteindre du statut social qu'ils visent par le financement des biens publics à titre privé, leurs contributions deviennent des compléments stratégiques. Dans ce cas, le niveau agrégé des biens publics croît avec la réduction des écarts de revenus entre les agents. Dans un scénario de transparence fiscale, les subventions ont un impact ambigu sur le niveau global des biens publics. Dans tous les cas, injecter de la compétition pour le statut social dans des fonctions d'utilité augmente les contributions aux biens publics, et donc leur niveau global, faisant de la concurrence une incitation féconde pour résoudre le problème du passager clandestin.
\end{abstract}

Mots clés : provision privée des biens publics, déculpabilisation, statut social, compétition, transfert de revenu, subventions.

This paper compares guilt alleviation and competition for social status in the private provision of a public good. When agents are intrinsically impulsed, that is, they mostly provide the public good in order to alleviate their guilt, they tend to free-ride. In contrast, when agents are extrinsically impulsed and compete for social status, their provisions become strategic complements. In the latter case, the aggregate level of the public good increases as the disparity between agents' incomes shrinks. In the see-through scenario, subsidizing has an ambiguous impact on the aggregate level of the public good. In any case, injecting competition for social status into utility functions increases provisions to a public good, and hence its aggregate level. Market competition thus creates incentives to overcome the freeriding issue.

Keywords: public good private supply, guilt relieving, social status, competition, income transfer, subsidies.

Codes JEL : A13, C7, H2, H41.

\footnotetext{
CIRANO and École Polytechnique ParisTech. CIRANO, 2020 rue University, Montréal (QC) H3A 2A5 Canada, arnaud.dragicevic@cirano.qc.ca.

${ }^{\dagger}$ École Polytechnique ParisTech and LARSEN, Route de Saclay, 91128 Palaiseau, France, guy.meunier@gislarsen.org.
} 
"Guilt is the price we pay willingly for doing what we are going to do anyway." Isabelle Holland

\section{Introduction}

The voluntary offset market enables agents to pay for their negative externalities issued from carbon emissions by investing in projects that reduce emissions or sequester carbon, such as tree planting or renewable energy. The reduction of carbon emissions is a public good because, once provided, agents can enjoy the benefits devoid of rivalry, without excluding anyone from its consumption. Some people believe that the voluntary carbon offset market is inefficient. One of the arguments put forward is that offsetting validates polluting behavior. Likewise, offsetting is said to operate like charities: voluntary supplies never provide enough public good because of the free-rider incentive. And when private arrangements finance a public good, free-riding on other people's provisions is rational.

However, free-riding is limited to some extent because agents who purchase offsets may also derive private benefits. Olson (1965) advances the hypothesis that free-riding can be overcome through social incentives. According to him, agents do not privately supply a public good for its direct material benefit, but to achieve social objectives like prestige or respect; this would explain why individuals do less free-riding than what the economic theory suggests. Following this rationale, Hawkes et al. (1993) show that in ancient times hunters and gatherers tended to share their resources because the cost of exclusion from the group - where every agent prefers a supplier to a consumer as a neighbor - was too high to risk, thus making resources a public good.

This impure approach of pro-social behavior has been modeled by Andreoni (1990) who justifies private provisions in terms of warm-glow or joy-of-giving. Our approach differs from Andreoni's and rejoins Olson's, for we consider social status gained by agents who privately supply a public good from its relative perspective. As a matter of fact, supplying to the public good can generate the private benefits of guilt relief - which we find more convincing than 
warm-glow - and social status ${ }^{1}$. In the first case, agents want to feel better about themselves, because they want to recover self-esteem after producing a public bad. Indeed, guilt is the source of altruistic acts in subjects who cause harm (Regan 1971). If an agent feels guilty, because she believes she bears responsibility for carbon excesses, then guilt alleviation through carbon offsetting is a private benefit derived from the supply of the public $\operatorname{good}^{2}$. The motivation for it is internal. It is thus an intrinsic incentive. Previous work has indicated that guilt can significantly increase an individual's likelihood of engaging in charitable behavior (Strahilevitz and Myers 1998). A major element in generating charitable donations through the use of guilt appeals instills a sense of responsibility to help (Basil et al. 2001). Responsibility may stem from causing something to occur or from failing to avoid the arrival of some occurrence (Miceli 1992). Since guilt is positively related to donation (Hibbert et al. 2007), guilt alleviation has a positive impact on the environmental awareness.

In parallel, agents compete to be formally acknowledged as being the most concerned about the public good. This prosocial behavior can be due to social pressure and norms and corresponds to an extrinsic incentive. An agent who offsets receives a proof acknowledging her provision to the public good. She thus sends a signal to make other agents aware of her polluting abatement. Following this rationale, producers will also promote their offsets as part of their corporate social responsibility policy (Kotchen 2009). People have a preference for showing altruism in situations that facilitate broadcast opportunities, and the provision of a public good is certainly one such situation (Smith and Bliege Bird 2000). If high status brings with it high earnings, then status seeking behavior can be explained as a part of economic behavior (Ball and Eckel 1998). According to competitive altruism, despite the dearness of being publicly generous, agents can promote their generosity as potential exchange partners, reaping the benefits later on (Roberts 1998). Agents also refuse transactions that are in their best economic interest when they feel they are an insult to their dignity (Bénabou and Tirole 2006). Experimental literature has confirmed the role of individual status as an incentive affecting market outcomes (Ball et al. 2001) and donors (Duffy and Kornienko 2005). Because of the rivalry and excludability in social

\footnotetext{
${ }^{1}$ Neither effect is exclusive, feelings being rarely disconnected. We just specify the domination of a motivation over another.

${ }^{2}$ Gilbert (1997) speaks about membership guilt over group wrongs. This collective guilt will be shared by members of the collective in question in their capacity as group members.
} 
hierarchy, agents have to compete before attaining some desired social status: if an agent desires to be the first or among the first in some venture, she might have to make the most efforts to reach her goal. Making the most efforts means that she has knowledge of her challengers and of the efforts she has to invest. De facto, what type of incentives should be introduced to increase private provisions? How does competition influence an agent's supply of a public good? Do agents become more generous by guilt or by craving for social status? For example, competitive mechanisms such as contests have shown to increase the voluntary provision of a public good (Kolmar and Wagener 2008).

This paper investigates how competition influences private provisions of the public good when agents are stirred by an intrinsic impulse, meaning that they mainly maximize utility from guilt relief, as opposed to when they are stirred by an extrinsic impulse, suggesting that they mainly maximize utility from social status. The paper answers the current call for understanding the behavior of individual consumers in the voluntary offset market (House of Commons 2007) and more generally how private agents behave toward public goods in a competitive setting. Our public goods game unveils several results: first, we find that when status seeking dominates guilt relief, private provisions become strategic complements: an attribute which increases the aggregate level of the public good. We prove sufficient conditions for existence and uniqueness of a Nash equilibrium. We then show that when agents behave according to their best-response functions, the aggregate level of the public good depends on the disparity between agents' incomes, which - depending on the nature of the provisions - induces a particular income transfer policy. At last, we prove that in case of see-through, subsidies have an ambiguous impact on the aggregate level of the public good.

We give a basic account of the social status function and present the public goods game in Section 2. In Section 3, we analyze the impact of a fiscal policy on the best response functions. Section 4 discusses the social optimum characteristics. We provide a representative model with logarithmic preferences and describe explicit properties of equilibria in Section 5. Section 6 concludes.

\section{The public goods game}


Let us consider two agents $i$ and $j$, with $j \neq i$. Let $w_{i}$ be agent $i$ 's endowment, let $x_{i}$ denote her consumption of the private good, let $G$ be the aggregate level of public good and let $g_{i}$ account for her provision to the public good. The aggregate level of public good is the sum of the two agents' provisions $G=g_{i}+g_{j}$. The relief of an agent is not exclusory with regard to the other agent. Private contributions due to guilt are thus additive. On the other side, agent $i$ 's social status $^{3}$ is determined by her relative contribution $s_{i}=g_{i}-g_{j}$. Indeed, as reported by Auriol and Renault (2008), social status is a scarce resource: increasing an agent's status requires that another agent's status decreases. Agents now have preferences represented by the following utility function

$$
u_{i} \equiv u_{i}\left(x_{i}, G, s_{i}\right)
$$

Considering agent $j$ 's provision $g_{j}$ as exogenous, agent $i$ maximizes her utility by solving the following program

$$
\max _{x_{i}, g_{i}} u_{i}\left(x_{i}, G, s_{i}\right) \text { subject to } x_{i}+g_{i}=w_{i} \text { and } g_{i} \geq 0
$$

Let us now determine the Nash equilibrium of the public goods game. Each agent's bestresponse function fully specifies her equilibrium strategy. This strategy involves choosing a level of private supply to the public good. We first analyze the best response functions of each agent. We thus study the two motives for contributing to the public good: to relieve guilt and to acquire social status.

Assume the marginal utility from the provision to the public good to be

$$
H_{i}\left(x_{i}, G, s_{i}\right)=\frac{\partial u_{i}}{\partial G}+\frac{\partial u_{i}}{\partial s_{i}}-\frac{\partial u_{i}}{\partial x_{i}}
$$

\footnotetext{
${ }^{3}$ A status-based model of market competition has previously been introduced by Podolny (1993).
} 
The first term denotes the marginal utility from the public good. The second term represents the marginal efficacy of social status. The last term is the marginal fall in the consumption of private goods. We then make three assumptions on $H$.

$$
\frac{\partial H_{i}}{\partial x_{i}}=\frac{\partial^{2} u_{i}}{\partial x_{i} \partial G}+\frac{\partial^{2} u_{i}}{\partial x_{i} \partial s_{i}}-\frac{\partial^{2} u_{i}}{\partial x_{i}^{2}}>0
$$

(A1) says that an increase of income increases the marginal utility of the supply of the public good. The assumption is referred to as the normality assumption because it is satisfied if we assume that both private and public goods are normal with respect to income. It simply says that agent $i$ 's demand for the public good increases with income and her demand for private goods does not decrease with income.

$$
\frac{\partial H_{i}}{\partial G_{i}}=\frac{\partial^{2} u_{i}}{\partial G^{2}}+\frac{\partial^{2} u_{i}}{\partial G \partial s_{i}}-\frac{\partial^{2} u_{i}}{\partial G \partial x_{i}}<0
$$

(A2) states that the marginal utility of the supply of the public good decreases with $G$. As a matter of fact, if the level of the public good increases independently of agent $i$ 's supply, there is no incentive to contribute to the public good. This is a formal foundation for the free-riding issue. Considering negative externalities, it simply means that any agent can compensate for the damage caused, and all agents can profit from its reparation ${ }^{4}$.

$$
\frac{\partial H_{i}}{\partial s_{i}}=\frac{\partial^{2} u_{i}}{\partial s_{i} \partial G}+\frac{\partial^{2} u_{i}}{\partial s_{i}{ }^{2}}-\frac{\partial^{2} u_{i}}{\partial s_{i} \partial x_{i}}<0
$$

(A3) implies that an increase in social status creates negative incentives: the agent tends to reduce her supply to the public good, because she no longer has to compete for social status.

Given the three assumptions and following the work by Andreoni (1990), we now consider that individuals obtain guilt relief and social status from their private supply of the

\footnotetext{
${ }^{4}$ According to Gilbert (1997) since feeling guilt is unpleasant, it is liable to move one who feels it to act. And this will not necessarily be the personal undertaking of reparative action.
} 
public good. Following the first order condition, agent $i$ 's best response, that is, $r_{i}\left(w_{i}, g_{i}\right)$, is to have $g_{i}$ such as

$$
r_{i} \equiv H\left(w_{i}-g_{i}, g_{i}+g_{j}, g_{i}-g_{j}\right)=0
$$

A Nash equilibrium of the public goods game is a couple of strategies $g_{i}^{*}, g_{j}^{*}$ such that each strategy is the best response to the other agent's strategy

$$
g_{i}^{*}=r_{i}\left(w_{i}, g_{j}^{*}\right) \text { with } j \neq i
$$

Let us now look at the second order condition to see whether contributing to the public good does in fact maximize an agent's function. The second order condition is satisfied for

$$
\frac{d H_{i}}{d g_{i}}=\frac{\partial H_{i}}{\partial G_{i}}+\frac{\partial H_{i}}{\partial s_{i}}-\frac{\partial H_{i}}{\partial x_{i}}<0
$$

The sign of the differential implies a diminishing marginal utility of the public good as the agent supplies the public good. Negativity depends on three terms. The first term measures the outcome of any provision to the public good on the marginal utility of the public good. This is our indicator of free-riding. The second term values the outcome of a shift in the social status on the marginal utility of the supply of the public good. It allows us to study the interactions between the aggregate level of the public good and the social status in the utility function. The third term assesses the impact of a decrease in private goods' consumption on the marginal utility of the public good.

The effect of agent $j$ 's supply on the marginal utility of agent $i$ 's supply is

$$
\frac{d H_{i}}{d g_{j}}=\frac{\partial H_{i}}{\partial G_{i}}-\frac{\partial H_{i}}{\partial s_{i}}
$$


This effect is ambiguous, for the first term is negative while the second one is positive. The first term denotes a typical free-riding issue: an increase of agent $j$ 's provision reduces agent $i$ 's incentive to contribute; except that the second term denotes status seeking, thus an opposite effect, as social status decreases with agent $j$ 's supply. Indeed, agent $i$ suffers from the reduction in the level of public good, thus any private provision that increases the public good also increases agent $i$ 's utility. Provided that any supply removes her feelings of guilt, she can freeride on others' provisions and allocate all her endowment to the private goods instead. This is a counter-incentive to supply the public good. In parallel, agent $i$ suffers from status loss in social status pursuit every time others supply the public good. Therefore $g_{j}$ is also an incentive to contribute in order to maintain the level of social status.

The sign of the best-response function slope of agent $i$ is

$$
\frac{\partial r_{i}}{\partial g_{j}}=\frac{d H_{i} / d g_{j}}{-d H_{i} / d g_{i}}
$$

The sign depends on which effect prevails: guilt relieving or status seeking. According to the terms of Bulow et al. (1985), if free-riding dominates social status pursuit or $\partial r_{i} / \partial g_{j}<0$, we are in presence of strategic substitutes, and strategic complements vice versa. Despite the fact that in the standard public goods games the only effect at stake is free-riding (even in the presence of an impure public good) and public good provisions are always strategic substitutes: injecting competition for social status converts the provisions into strategic complements in some cases.

A Nash equilibrium is a set of provisions that satisfies the aggregation of supplies. Let us prove its existence and uniqueness. For a Nash equilibrium to exist, one must verify

$$
\frac{d H_{i} / d g_{j}}{-d H_{i} / d g_{i}}, \frac{d H_{j} / d g_{i}}{-d H_{j} / d g_{j}} \in(-1,1)
$$

The slopes of the best-response functions are bounds within the interval $(-1,1)$. The binding conditions are sufficient for the existence of a unique Nash equilibrium. 
Proposition 1: If (8) is satisfied, there exists a unique Nash equilibrium.

Let us now see what happens when the policy of income transfer is instituted. Consider the ratio which confronts the two motives involved in the public good's supply. The expression returns to an intrinsic impulse coefficient such as

$$
\gamma_{i}=\frac{\partial H_{i} / \partial x_{i}}{\left(\partial H_{i} / \partial x_{i}\right)-\left(2 \partial H_{i} / \partial s_{i}\right)}
$$

The numerator measures the marginal utility of the public good and stands for the intrinsic (contrite) impulse of guilt relief to supply the public good. It depends on agent $i$ 's income and thus on her opportunity loss when she does not purchase the private goods. Here, agent $i$ is indifferent between consuming her own supply or benefiting from agent $j$ 's supply of the public good. In Andreoni's terminology, this phenomenon means pure altruism or selflessness of agent $i$. We consider the numerator as a measure of free-riding on others' provisions instead.

The denominator represents the influence of social status on the marginal utility of the supply of the public good and stands for the extrinsic (social) impulse of status seeking to supply the public good. Just as with the numerator, it depends on agent $i$ 's income, but it depends on social status above all, that is, marginal utility of the public good derived from her own provision (analogue to impure altruism). Given that status is acquired by relative provisions, the effect of social status counts twice. First, consuming more of the $x$ 's decreases agent $i$ 's provision to the public good and thus her social status; second, more of $g_{j}$ implies lower social status for agent $i$, all else being equal. For those reasons, the intrinsic impulse coefficient is inversely proportional to status seeking.

Proposition 2: An income transfer from agent $j$ to agent $i$, such that $d w_{i}=-d w_{j}>0$ increases $G$ if and only if $\gamma_{i}>\gamma_{j}$.

Agents are unwilling to perfectly substitute their provisions to offset a transfer. If $\gamma_{i}>\gamma_{j}$ then agent $i$ is less status seeking than agent $j$. Hence, the policy of income transfer will increase 
(decrease or not change) the aggregate level of the public good if and only if the income gainer is less status seeking than (more status seeking than or equally status seeking than) the income loser, because the former has lower incentives to supply than the latter. This proposition is comparable to that of Andreoni, but our interpretation is dissimilar. In fact, since competition for social status encourages agents to supply the public good, only an increase in income will motivate the lower income agent to supply more ${ }^{5}$, for it enables her to compete for social status. In equilibrium, she will allocate the increase in income in both private and public goods. Without transfer, her position discourages her to race for social status and she can only relieve her guilt. The direct consequence is free-riding on other agents' provisions. Another way of understanding the proposition is: since the higher income agent proves - with a higher level of supply which reflects higher income - to be more extrinsically impulsed, she does not have to contribute more to the public good. She is in no doubt to hold the social status ex ante.

Our model is a way-out to impure altruism and warm-glow giving. We identify pure altruism as guilt relief and thus free-riding, while impure altruism corresponds to the willingness to compete for social status, which is observable via any non-anonymous donation. The model is thus an alternative and a more realistic way to explain prosocial behavior, especially when agents compete to publicly offset a public bad.

\section{Fiscal policy}

Assume that the government subsidizes private supplies at a rate $\sigma$, and pays for this subsidy by levying a lump-sum tax $\tau$. All net fiscal receipts fund the public good.

Let $T=2 \tau-\sigma\left(g_{i}+g_{j}\right)$ be the aggregate net fiscal receipts, and let $Y=G+T$ be the joint supply of the public good composed of both the agents' provisions and the government's fiscal receipts. We consider that agents anticipate the governmental reaction to their choices. This hypothesis was defined by Boadway et al. (1989) as see-through. The see-through agents know that when they increase their private provisions, the government provides less due to lower fiscal

\footnotetext{
5 For example, OECD (2007) suggests monetary transfers in benefit of low income households when imposing environmental taxes.
} 
receipts. The strategic variables are $y_{i}$ and $y_{j} ; y_{i}=g_{i}(1-\sigma)+\tau$ which includes voluntary supply and tax components is agent $i$ 's total contribution to the public good. Preferences become

$$
u_{i} \equiv u_{i}\left(x_{i}, Y, s_{i}\right)
$$

The social status of agent $i$ is determined by her private supply

$$
g_{i}=\frac{y_{i}-\tau}{1-\sigma} \text { thus } s_{i}=\frac{y_{i}-y_{j}}{1-\sigma}
$$

Subsidizing works as a multiplying effect and reinforces the incentive to privately supply. Moreover, subsidies have a direct effect on the social status. With higher subsidies and fixed total contribution, agents' private supplies as well as the difference between social statutes rise.

Agent $i$ 's budget constraint is subsequently rewritten $x_{i}+y_{i}=w_{i}$. Her best response $r_{i}\left(w_{i}, y_{j}\right)$ with $j \neq i$ is to have $y_{i}$ such as

$$
r_{i} \equiv F\left[w_{i}-r_{i}, r_{i}+y_{j}, \frac{1}{1-\sigma}\left(r_{i}-y_{j}\right)\right]=0
$$

A Nash equilibrium of the public goods game is a couple of strategies $y_{i}^{*}, y_{j}^{*}$ such that each strategy is the best response to the other agent's strategy $y_{i}^{*}=r_{i}\left(w_{i}, y_{j}^{*}\right)$ with $j \neq i$

$$
\frac{\partial F}{\partial y_{i}}=\frac{\partial F}{\partial Y}+\frac{\partial F}{\partial s_{i}} \frac{1}{1-\sigma}-\frac{\partial F}{\partial x_{i}}, \frac{\partial F}{\partial y_{j}}=\frac{\partial F}{\partial Y}-\frac{\partial F}{\partial s_{i}} \frac{1}{1-\sigma}
$$

Let us now take a further look at the effect of the subsidy on the reaction function; the partial derivative yields the following

$$
\frac{d F}{d \sigma_{i}}=\frac{1}{(1-\sigma)^{2}} \frac{\partial u}{\partial s_{i}}+\frac{1}{1-\sigma} \frac{\partial}{\partial s_{i}}\left[\frac{\partial u}{\partial Y}+\frac{\partial u}{\partial s_{i}} \frac{1}{1-\sigma}-\frac{\partial u}{\partial x_{i}}\right]
$$


The effect of subsidizing private supplies is ambiguous, for the first term is positive while the second one is negative. The first term represents the multiplying factor from the subsidy: by means of $Y$, an increase in subsidizing reinforces the incentive to supply and provides more social status to the agent. On the contrary, due to (A3), the agent tends to reduce her supply to the public good. This is captured by the second term.

Proposition 3: Given preferences of the form $u_{i}\left(x_{i}, Y, s_{i}\right)$ and an interior equilibrium, $(i)$ an increase in the lump-sum tax $\tau$ leaves the aggregate level of the public good unchanged: the crowding-out is complete; (ii) an increase in subsidies $\sigma$ gives an ambiguous outcome on the aggregate level of the public good: the crowding-out is unknown.

First, similarly to the pure public good scenario without see-through, and contrary to Andreoni's Proposition 3(a), our results show no influence of the lump-sum tax, which translates the inconsequence of the level of taxation. Indeed, raising taxes makes people contribute less by the amount of fiscal receipts. The crowding-out is complete and public and private supplies are totally substitutable; a dollar spent on taxes provides the same stimulus to private supplies than a dollar of direct grants.

Second, contrary to the pure public good scenario with see-through, and similarly to Andreoni's Proposition 3(b), our results show high influence of the subsidy, that is, we are in presence of a multiplying factor of subsidies which was previously termed as greater stimulus to charity. Imparting subsidizing incites agents to contribute more than by the amount of the government's expenditures. At this point of analysis, the crowding-out is incomplete and public and private supplies are imperfect substitutes; a dollar spent on subsidies provides a greater stimulus to private supplies than a dollar of direct grants. However, additional social status discourages agents to privately supply. In conclusion, the crowding-out is unknown.

Let us now study the influence of subsidizing on the intrinsic impulse coefficient

$$
\gamma_{i}^{\prime}=\frac{\partial F_{i} / \partial x_{i}}{\left(\partial F_{i} / \partial x_{i}\right)-\left[2 \partial F_{i} /(1-\sigma) \partial s_{i}\right]}
$$


As $\sigma \rightarrow 1, \gamma_{i}^{\prime} \rightarrow 0$, which implies that subsidizing reinforces the pursuit of social status, for it works as a multiplying factor on the extrinsic motivation. Yet, the higher the subsidizing, the higher the contributing, as subsidizing provides social status for free. We also know that higher social status creates negative incentives to privately supply the public good. Therefore, subsidizing has an ambiguous impact on private supplies, because agents can obtain social status without increasing their provisions to the public good. Due to see-through, agents are aware of the governmental gifting that replaces its direct granting to the public good.

\section{Social optimum}

A social Pareto optimum is a repartition of contributions that maximizes a weighted welfare function

$$
W=u_{i}+\lambda u_{j}
$$

where $\lambda$ represents the weight of agent $j$ 's utility. With fixed revenues $w_{i}, w_{j}$ first order conditions are

$$
\frac{d u_{i}}{d g_{i}}+\lambda \frac{d u_{j}}{d g_{i}}=0
$$

and subsequently

$$
\frac{d u_{i}}{d g_{i}}=\frac{\partial u_{i}}{\partial G}+\frac{\partial u_{i}}{\partial s_{i}}-\frac{d u_{i}}{d x_{i}}=F_{i}
$$

The effect from the contribution of agent $i$ on agent $j$ 's utility is

$$
\frac{d u_{j}}{d g_{i}}=\frac{\partial u_{j}}{\partial G}-\frac{\partial u_{j}}{\partial s_{j}}=F_{j}
$$


The first term is the public good dimension of agent $i$ 's supply and represents a positive externality of her contribution on agent $j$ 's utility; it possibly indicates agent $i$ 's suboptimal contribution. The second term is the private good dimension of agent $i$ 's supply and represents a negative externality on the social status of agent $j$. Which term dominates determines the impact of agent $i$ 's actions on agent $j$.

At the social optimum, we have

$$
F_{i}+\lambda \frac{d u_{j}}{d g_{i}}=0, F_{j}+\frac{1}{\lambda} \frac{d u_{i}}{d g_{j}}=0
$$

The two equations determine a Pareto optimal couple of contributions $g_{i}, g_{j}$. The ambiguity of the sign of the externality implies an unclear outcome on the social optimum at interior equilibrium: it is unclear whether an agent undercontributes or overcontributes as regards the social optimum. In case of undercontribution, we face the issue of the weak version of the free-riding hypothesis, where the public good is provided, but its allocation is suboptimal (Brubaker 1975).

Let us now study the social optimum in presence of a fiscal policy. Let us denote $y_{i}(\sigma), y_{j}(\sigma)$ the Nash equilibrium with fiscal policy

$$
W=u_{i}\left(w_{i}-y_{i}, Y, s_{i}\right)+u_{j}\left(w_{j}-y_{j}, Y, s_{j}\right)
$$

The effect of a change in subsidy amounts to

$$
\frac{\partial W}{\partial y_{i}} \frac{\partial y_{i}}{\partial \sigma}+\frac{\partial W}{\partial y_{j}} \frac{\partial y_{j}}{\partial \sigma}+\frac{\partial W}{\partial \sigma}
$$

which yields 


$$
\left[\frac{d u_{j}}{d y_{i}}+\frac{d u_{i}}{d y_{i}}\right] \frac{\partial y_{i}}{\partial \sigma}+\left[\frac{d u_{i}}{d y_{j}}+\frac{d u_{j}}{d y_{j}}\right] \frac{\partial y_{j}}{\partial \sigma}+\left[\frac{\partial u_{i}}{\partial s_{i}} \frac{y_{i}-y_{j}}{(1-\sigma)^{2}}+\frac{\partial u_{j}}{\partial s_{j}} \frac{y_{j}-y_{i}}{(1-\sigma)^{2}}\right]
$$

The first two terms represent the effect of the subsidy on the contributions to the public good. The third term encapsulates the multiplying effect of the subsidy on social status. By the envelope theorem, the precedent becomes

$$
\frac{d u_{j}}{d y_{i}} \frac{\partial y_{i}}{\partial \sigma}+\frac{d u_{i}}{d y_{j}} \frac{\partial y_{j}}{\partial \sigma}+\left[\frac{d u_{i}}{d s_{i}}-\frac{d u_{j}}{d s_{j}}\right] \frac{y_{i}-y_{j}}{(1-\sigma)^{2}}
$$

In the end, we obtain

$$
\left[\frac{\partial u_{i}}{\partial G}-\frac{\partial u_{i}}{\partial s_{i}}\right]+\left[\frac{\partial u_{j}}{\partial G}-\frac{\partial u_{j}}{\partial s_{j}}\right]+\left[\frac{d u_{i}}{d s_{i}}-\frac{d u_{j}}{d s_{j}}\right] \frac{y_{i}-y_{j}}{(1-\sigma)^{2}}
$$

The expression divulges a compound ambiguous effect. The two first terms represent the effect of an agent's supply on the marginal utility of the other agent's supply. We learn from Section 1 that this effect is ambiguous, and depends on the predominance of social status. The third term illustrates the impact of subsidies on social status. Once again, the effect is ambiguous, for both factors have an ambiguous sign. However, note that if $y_{i}>y_{j}$, it is likely that the agent $i$ 's marginal reward from social status, that is $\partial u_{i} / \partial s_{i}$, is lower than the marginal reward of agent $j$, or $\partial u_{j} / \partial s_{j}$, suggesting a positive sign. When social statuses are equal and agents are symmetric, the term vanishes.

Proposition 4: Subsidies increase the difference in social status between agents.

It is straightforward to see that an increase in subsidies expands the disparities between social statuses. Those who already held social statuses by providing higher private supplies obtain additional status for free, enlarging the fore social distance. This result implies that high levels of subsidizing can worsen the distance to social optimum of the public good. 
Concerning Paretian optimality, agents can always choose to contribute less than what is socially optimal while gaining social status due to see-through. It means that in presence of subsidies, corner equilibria do not arise, because agents are always incited to contribute a positive amount. Nevertheless, we can allude that if social status strongly dominates guilt relief, there is an inevitable breaking point from which subsidies no longer increase private supplies up to the social optimum, due to the gratuitousness of the additional social status that they provide.

\section{The logarithmic model}

\subsection{The explicit program}

Following the model by Kumru and Vesterlund (2008) and Munoz-Garcia (2009), agents have preferences represented by a separable nonlinear utility function. The explicit maximization program is then

$$
\begin{gathered}
\max _{x_{i}, g_{i}} u\left(x_{i},\left(g_{i}, g_{j}\right), s\right)=\ln \left(w_{i}-g_{i}\right)+\ln \left[\alpha_{i}\left(g_{i}+g_{j}\right)+\beta_{i}\left(g_{i}-g_{j}\right)\right] \\
\text { subject to } x_{i}+g_{i}=w, g_{i} \geq 0
\end{gathered}
$$

where $G=g_{i}+g_{j}$ and $s_{i}=g_{i}-g_{j}$. The first term represents the utility derived from the consumption of private goods $x_{i}$. The second term corresponds to the utility that agent $i$ obtains from her supply of the public good, which is nondecreasing in $g_{i}$.

We assume that individuals originate guilt relief from their private supply to the public good. Agent $i$ 's preferences when she provides the public good by $g_{i}$ are defined by

$$
\alpha_{i}\left(g_{i}+g_{j}\right) \text { for } j \neq i
$$


The expression denotes the utility that agent $i$ gets from the aggregate level of the public good scaled by a specific index $\alpha_{i} \geq 0$ : some willingness to alleviate guilt is expressed by either agent $^{6}$.

Agent $i$ gets utility from social status when she provides the public good by $g_{i}$. Her status is given by the distance between her provision and that of agent $j$ 's such as

$$
\beta_{i}\left(g_{i}-g_{j}\right) \text { for } j \neq i
$$

Agent $i$ enhances her status in the social hierarchy if her provision outdistances agent $j$ 's; otherwise, her social status deteriorates. The status is scaled by a specific index $\beta_{i}$, with $\beta_{i} \geq 0$, which measures agent $i$ 's willingness to pursue social status. When agents provide identical provisions, the term vanishes. In the equilibrium, agent $i$ knows whether she acquires social status through her private supply of the public $\operatorname{good}\left(g_{i}>g_{j}\right)$.

We thus see that agent $j$ 's provision is both a strategic substitute and a strategic complement of agent $i$ 's utility. As a strategic substitute, two obvious interpretations come out. First, agent $i$ suffers from the public bad, thus any private provision that increases the public good also increases agent $i$ 's utility. Second, since any provision can remove her feelings of guilt, she can free-ride on others' provisions and allocate all her endowment to the consumption of the private goods. To consider agent $j$ 's provision as a strategic complement is to consider that agent $i$ suffers from status loss in social hierarchy every time agent $j$ provides the public good. In this case, agent $j$ 's private provision decreases agent $i$ 's utility.

\subsection{Reaction functions}

Now suppose both agents decide to submit their provisions to the public good. Given $g_{j}$, differentiating $u(\cdot)$ with respect to $g_{i}$ gives $r_{i}$, agent $i$ 's best-response function

\footnotetext{
${ }^{6}$ Social comparison theory suggests that individuals have a need to compare themselves to individuals whom they deem are similar to them (Goethals 1986).
} 


$$
r_{i}\left(w_{i}, g_{j}\right)=\frac{1}{2} w_{i}-\frac{A_{i}}{2} g_{j} \text { if } g_{j}<\max \left\{\frac{w_{i}}{A_{i}},-\frac{w_{i}}{A_{i}}\right\}
$$

where $A_{i}=\left(\alpha_{i}-\beta_{i}\right) /\left(\beta_{i}+\alpha_{i}\right)$. Whether $r_{i}$ is constrained depends on the level of $g_{j}$. For small values of $g_{j}$, agent $i$ allocates a part of her income to the supply of the public good. For sufficiently high values of $g_{j}$, agent $i$ can supply either nothing or her full income. Whichever occurs depends on the sign of $\beta_{i}-\alpha_{i}$.

Corollary 1: The difference between $\beta_{i}$ and $\alpha_{i}$ determines whether provisions are strategic substitutes or strategic complements.

When $\alpha_{i}>\beta_{i}$ or $A_{i}>0, r_{i}$ is the best-response only when $g_{j} \leq w_{i} / A_{i}$, which is a nonnegative number. If agent $j$ surpasses this threshold, agent $i$ has fairly no incentive to make positive provisions. In point of fact, even a quasi-null level of $g_{i}$ (nonnegative by definition) enables agent $i$ to maximize her utility by allocating her income to more private goods while alleviating her guilt through agent $j$ 's provisions. We could think of an agent who pays tribute to the collective high efforts in providing the public good while ending up self-pleased by giving a single coin.

When $\alpha_{i}=\beta_{i}$ or $A_{i}=0$, agent $i$ is equally concerned by guilt alleviation and social hierarchy. This time, $r_{i}$ is equal to $(1 / 2) w_{i}$ for $g_{j} \in[0, \infty]$. Her provision is always the half of her income, but she has no incentive to contribute more than that. This is the behavior of an autonomous agent who disregards the provisions of the opponent. We could think of an agent who invariably contributes to the public good in order to alleviate her guilt - because some moral obligation incites her to do so -, but who does not discredit the positive spillover on her social rank, even if she is not centered upon the social ranking matter. This agent denies the possibility of acting as a free-rider.

At last, when $\alpha_{i}<\beta_{i}$ or $A_{i}<0, r_{i}$ holds if $g_{j} \leq-w_{i} / A_{i}$, otherwise $r_{i}=w_{i}$ and agent $i$ allocates her full income to the supply of the public good. Provisions are then strategic 
complements: every time agent $j$ increases her supply, agent $i$ has an incentive to increase her supply to stay in the race for the social status up to the point where her full income is spent.

According to the foregoing results, Fig. 1. illustrates the best-response functions which meet at the bisection line, observed from symmetric cases $\alpha_{i}=\alpha_{j}=\alpha$ and $\beta_{i}=\beta_{j}=\beta$. Each best-response function - initiated from the reference point which is the opponent's null provision - is v-shaped, i.e. separated into two segments following opposite slopes.

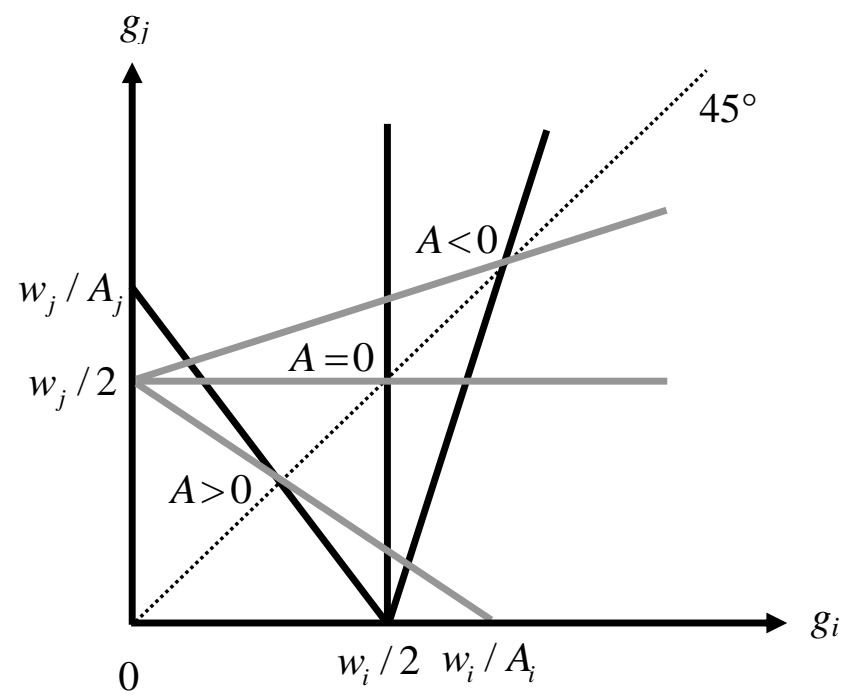

Fig. 1. Agents $i$ 's and $j$ 's best-response functions

The black straight lines depict agent $i$ 's best-response functions. The grey straight lines depict agent $j$ 's best-response functions. We have three cases: $(i)$ when the intrinsic impulse dominates $A>0$, their best-response functions decrease in their opponents' provisions and the public good is weakly provided, for respective provisions are less than $w_{i} / 2, w_{j} / 2$; (ii) when the extrinsic impulse dominates $A<0$ their best-response functions increase in their opponents' provisions and the public good is highly provided, equilibrium provisions' exceed $w_{i} / 2, w_{j} / 2$; (iii) when impulses are identical $A=0$, equilibrium provisions are $w_{i} / 2, w_{j} / 2$.

\subsection{The equilibrium}


At a Nash equilibrium $\left(g_{i}^{*}, g_{j}^{*}\right)$ each agent's provision is her best response to the other's. We first consider an interior equilibrium where both agents' provisions are strictly positive but inferior to their incomes: $0<g_{i}^{*}<w_{i}, 0<g_{j}^{*}<w_{j}$. At such equilibrium, provisions amount to

$$
g_{i}^{*}=\frac{2 w_{i}-A_{i} w_{j}}{4-A_{i} A_{j}}, g_{j}^{*}=\frac{2 w_{j}-A_{j} w_{i}}{4-A_{j} A_{i}}
$$

Where $A_{i}=\left(\alpha_{i}-\beta_{i}\right) /\left(\beta_{i}+\alpha_{i}\right)$ and $A_{i}=\left(\alpha_{j}-\beta_{j}\right) /\left(\beta_{j}+\alpha_{j}\right)$. In this case, the aggregate level of the public good in equilibrium, that is, $G^{*}=g_{i}^{*}+g_{j}^{*}$, amounts to

$$
G^{*}=\frac{1}{4-A_{i} A_{j}}\left[\left(2-A_{j}\right) w_{i}+\left(2-A_{i}\right) w_{j}\right]
$$

As one can detect, when agents apply their best-response functions, the aggregate level of the public good depends on the relative distance between the social status and guilt relief indices.

Corollary 2: When $A_{i}$ increases, ( $\left.i\right)$ the equilibrium provision of agent $i$ decreases; (ii) the aggregate equilibrium quantity of public good decreases; (iii) and the equilibrium provision of agent $j$ increases (decreases) if $A_{j}>(<) 0$.

A policy of income transfer from agent $j$ to agent $i$ such that $d w_{i}=-d w_{j}=1$ impacts the aggregate quantity of public good

$$
d G=d g_{i}+d g_{j}=\left[\frac{\partial g_{i}}{\partial w_{i}}-\frac{\partial g_{i}}{\partial w_{j}}\right]+\left[\frac{\partial g_{j}}{\partial w_{i}}-\frac{\partial g_{j}}{\partial w_{j}}\right]
$$

that is 


$$
d G=\frac{1}{4-A_{i} A_{j}}\left[A_{i}-A_{j}\right]
$$

where $A_{i}-A_{j}=2\left(\alpha_{i} \beta_{j}-\alpha_{j} \beta_{i}\right) /\left(\alpha_{i}+\beta_{i}\right)\left(\alpha_{j}+\beta_{j}\right)$.

Corollary 3: At interior equilibrium, an income transfer from agent $j$ to agent $i$ increases (decreases) the aggregate level of the public good if and only if $\alpha_{i} \beta_{j}-\alpha_{j} \beta_{i}>(<) 0$.

In equilibrium, when $\beta_{i}=\beta_{j}=0$ and each agent is indifferent between her supply and the other's supply, we have $d G=0$ which is the standard result of neutrality obtained by Warr (1983).

Let us now consider corner solutions with either null or full-income provisions. In corner equilibria, in case of strategic substitutes, one of the agents provides a null supply. In case of strategic complements, one of the agents allocates her full income to the public good supply. If we analyze income transfers at the corner equilibria in the symmetric case, Figs. 2. and 3. depict provisions with respect to the income inequality. The $x$-axes denote agents' shares of total income: $w_{i} /\left(w_{i}+w_{j}\right), w_{j} /\left(w_{i}+w_{j}\right)$. The $y$-axis represents the aggregate level of the public good. The total income is fixed. The broken black curve represents the provision of agent $i$ while the broken grey curve represents the provision of agent $j$. The broken grey curve decreases while the broken black curve increases as the transfer between agents $j$ and $i$ occurs. The equality arises at 0.5. The solid black curve illustrates the sum of provisions, i.e. the aggregate level of the public good. 


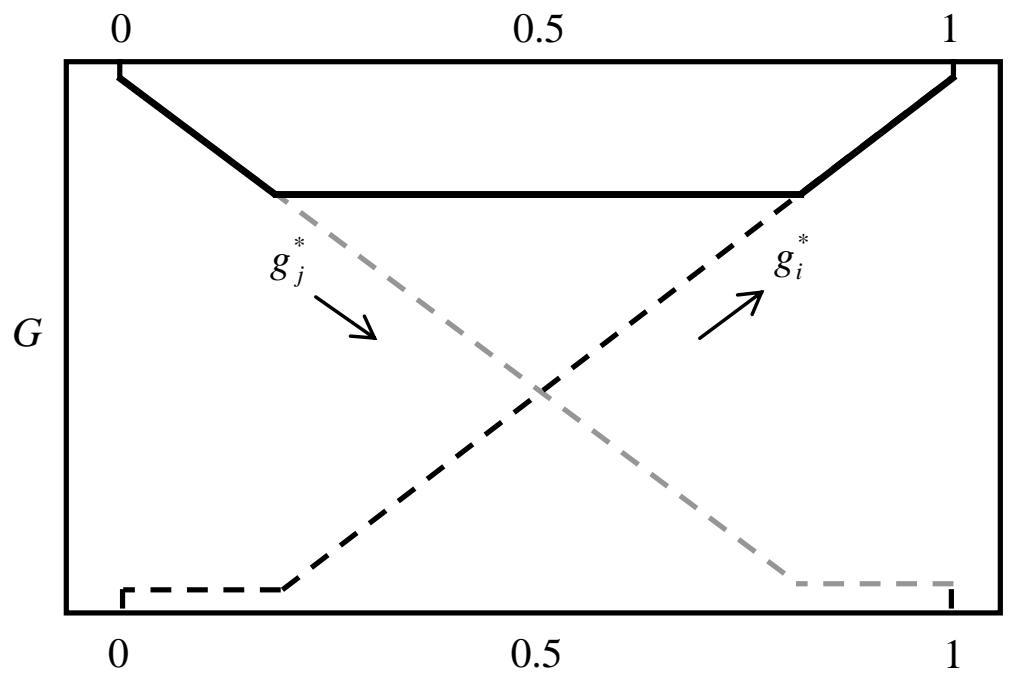

Fig. 2. Income transfer with strategic substitutes

In the case of strategic substitutes (the standard scenario in public goods games), the aggregate level of the public good decreases as the incomes' disparity shrinks. Indeed, at a corner solution, the lower income agent invariably free-rides on the supply of the higher income agent. If the income is transferred from the lower income agent to the higher income agent, the latter should allocate the extra income into the public good supply ${ }^{7}$ and the aggregate quantity should increase. This is a similar result to Theorem 5 from Bergstrom et al. (1986) who show that equalizing income by transferring income from contributors to non-contributors will decrease the equilibrium supply of the public good, in the case of a pure public good ( $\beta_{i}=0$ in our case).

\footnotetext{
${ }^{7}$ For example, this can suggest that cutting taxes on the higher income agent and raising taxes on the lower income agent may increase private supply.
} 




Fig. 3. Income transfer with strategic complements

In the case of strategic complements (the novel scenario in public goods games), the aggregate level of the public good decreases as the agents' income disparity grows. This time, the lower income agent allocates her full income to the supply of the public good in order to gain social status, thus saturating her supply capacity, whereas the higher income agent contributes less than her full income. An income transfer from the higher income agent to the lower income agent should increase the quantity of public good, because the lower income agent should allocate the money transfer to the provision of the public good.

At last, Fig. 4. shows the aggregate provisions to the public good in view of $A_{i}$ and $A_{j}$, in both interior and corner equilibria. The kinks in the slope correspond to corner equilibria. When $A_{i}<0$, agent $i$ 's provision is a strategic complement, and strategic substitute otherwise. $G$ decreases with $A_{i}$. 


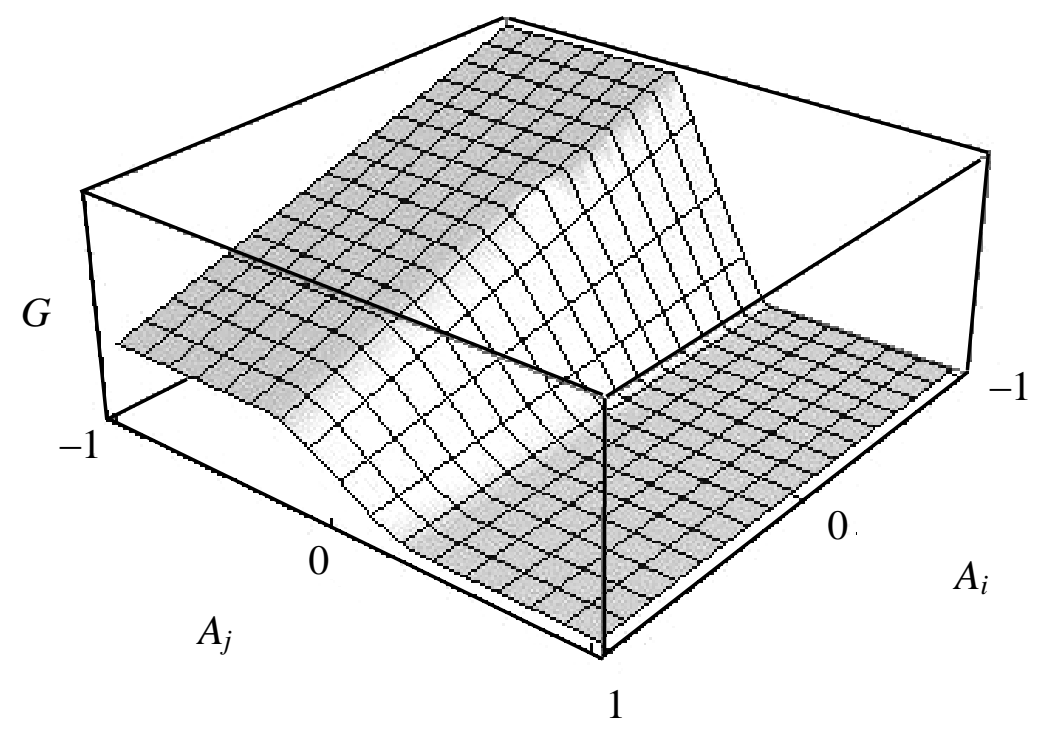

Fig. 4. The aggregate level of provisions

\subsection{Subsidizing}

Subsidies and taxes are now included in the utility maximization. The logarithmic program becomes

$$
\begin{gathered}
\max _{x_{i}, y_{i}} u \equiv \ln \left[w_{i}-\left(g_{i}(1-\sigma)+\tau\right)\right]+\ln \left[\alpha_{i}\left[(1-\sigma)\left(g_{i}+g_{j}\right)+2 \tau\right]+\beta_{i}\left[(1-\sigma)\left(g_{i}-g_{j}\right)\right]\right] \\
\text { subject to } x_{i}+g_{i}(1-\sigma)+\tau=w, g_{i} \geq 0
\end{gathered}
$$

which we can rewrite as

$$
\ln \left(w_{i}-y_{i}\right)+\ln \left[\alpha_{i}\left(y_{i}+y_{j}\right)+\frac{1}{1-\sigma} \beta_{i}\left(y_{i}-y_{j}\right)\right]
$$

As a result, the equilibrium level of contributing now equals

$$
y_{i}^{*}=w_{i}-y_{j} B_{i}, y_{j}^{*}=w_{j}-y_{i} B_{j}
$$


where $B_{i}=\alpha_{i}-\left[\beta_{i} /(1-\sigma)\right] / \alpha_{i}+\left[\beta_{i} /(1-\sigma)\right]$ and $B_{j}=\alpha_{j}-\left[\beta_{j} /(1-\sigma)\right] / \alpha_{j}+\left[\beta_{j} /(1-\sigma)\right]$. We see that the extrinsic motivation increases in $\sigma$, which illustrates the multiplying effect. When the social status pursuit dominates guilt relief, that is $y_{j} \leq-w_{i}$, any nonnegative amount enables agent $i$ to gain social status. In this case, the joint supply of the public good in equilibrium, that is $Y^{*}=y_{i}^{*}+y_{j}^{*}$, amounts to

$$
Y^{*}=\frac{1}{1-B_{i} B_{j}}\left[\left(1-B_{j}\right) w_{i}+\left(1-B_{i}\right) w_{j}\right]
$$

Corollary 4: At interior equilibrium, the governmental subsidizing of private supplies increases the aggregate level of the public good.

In detail, the equilibrium contribution of agent $i$ decreases with subsidizing, when the supply is a strategic substitute, if

$$
w_{i}>\frac{2+B^{2}}{B} w_{j}
$$

Corollary 5: An increase in governmental subsidizing (i) increases the agents' private supplies, when contributions are strategic complements; (ii) decreases agent i's private supply, when contributions are strategic substitutes, if and only if $w_{i}>w_{j}\left[\left(2+B^{2}\right) / B\right]$.

\subsection{Social optimum}

Following the separable nonlinear utility function, first order Pareto conditions with $\lambda=1$ and identical agents, that is, $\alpha_{i}=\alpha_{j}$ and $\beta_{i}=\beta_{j}$, yield 


$$
\left[\frac{\alpha+\beta}{\alpha\left(g_{i}+g_{j}\right)+\beta\left(g_{i}-g_{j}\right)}-\frac{1}{w_{i}-g_{i}}\right]+\frac{\alpha-\beta}{\alpha\left(g_{i}+g_{j}\right)+\beta\left(g_{j}-g_{i}\right)}=0
$$

Corollary 6: The difference between $\alpha$ and $\beta$ determines whether an agent's supply has $a$ positive or a negative externality on the utility of the other agent.

The sign of the effect, that is, the second term of the left hand side expression, is solely determined by the sign of $\alpha-\beta$. At an interior equilibrium, if $A>0$, we fall on the standard case where contributions act like strategic substitutes. Free-riding then implies social suboptimal provision of the public good. Likewise, if $A<0$, we observe social superoptimal provision of the public good. When supplies are strategic substitutes, the aggregate level of the public good is suboptimal8. However, it is unclear whether an agent makes either a larger or a smaller contribution than the socially optimal one. This ambiguity is linked to the substitutability aspect.

Let us consider the scenario where agent $j$ weekly free-rides, i.e. she undersupplies as regards the social optimum. Agent $i$ does not internalize the positive externality of her supply and provides less than what agent $j$ contributes in Nash equilibrium. In addition, her underprovision is either larger or lower than the social optimum. Graphically, we obtain the Nash and Pareto optima as follows.

\footnotetext{
${ }^{8}$ In case of strategic complements, there is no such ambiguity and each agent socially overcontributes: the public good is at a level higher than the social optimum.
} 


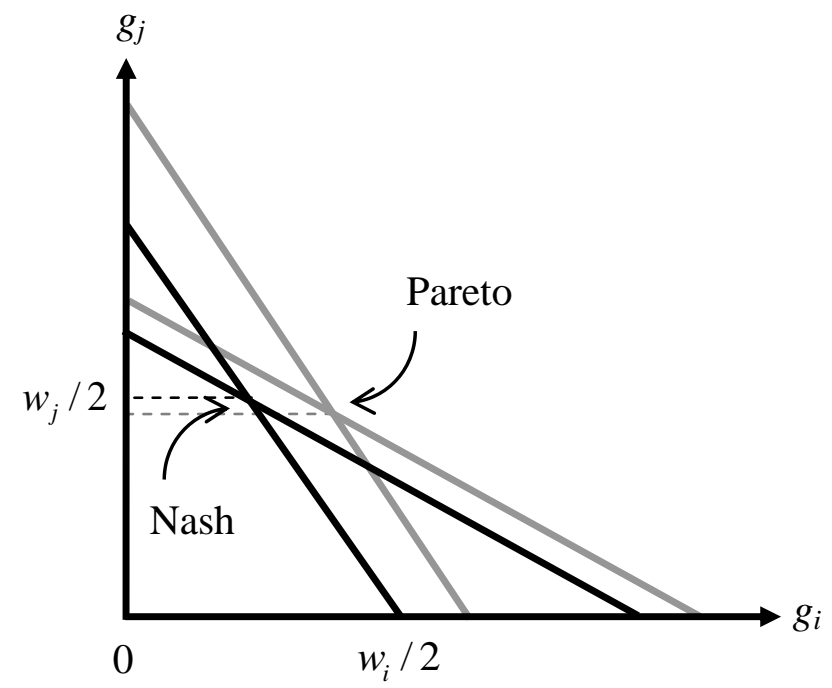

Fig. 5. Agents $i$ 's and $j$ 's socially optimal response functions

\section{Concluding remarks}

When agents privately provide a public good, agents profit from donations to alleviate their guilt. Because guilt relief entails opportunity costs, agents refuse to pay for others' guilt or simply profit from efforts of the others, and this leads to free-riding and weak provision of the public good: a phenomenon amply covered by the economic literature.

The private provision of the public good is stimulated by the private benefit of the public good such as obtaining some social status, which ex post seems intuitive. In the case where provisions become strategic complements, a policy of income transfers from the higher income agent to the lower income agent should increase the aggregate level of the public good. Its purpose would be to activate the competition for social status, which increases the public good's level and thus social welfare. Therefore, competition can be an efficacious anti-free-riding shield ${ }^{9}$.

Yet, contrary to a common thought, a policy of subsidizing has an ambiguous effect on private contributions, because it provides social status for free whenever agents are endowed with

\footnotetext{
${ }^{9}$ This is an opposite result to Holländer (1990) who finds that opening a market for the collective good lowers its provision.
} 
the see-through capacity; this policy can yield an outcome opposite to the aim of the government when it sets up subsidies.

In any case, our model can stand for the wanting theoretical background which explains why agents under-react to the income transfer, that is, why lower income agents over-contribute and higher income agents under-contribute, in both experiments from Chan et al. (1996) and Maurice et al. (2009). Indeed, neither has considered contributions as strategic complements. Besides, Chan et al. (1996) themselves conclude that the explanation for experimental results might be in a model where agents react to their competitors. Their intuition meets up with ours.

In general, our results could explain the institution of charity auctions, honor rolls of donors and the construction of socially responsible finance indices. More generally, it could relate to why institutions make use of agents' willingness to demonstrate their generosity if not their apparent selflessness. To some extent, our model could be an illustration of the theory of crowding out of intrinsic motivations by extrinsic incentives.

\section{References}

Andreoni, J. (1990), "Impure Altruism and Donations to Public Goods: A Theory of Warm-Glow Giving?”, Economic Journal, Royal Economic Society, 100: 464-477.

Auriol, E. and Renault, R. (2008), "Status and Incentives", RAND Journal of Economics, 39: 305-326.

Ball, S. and Eckel, C. (1998), "The Economic Value of Status", Journal of Socio-Economics, 27: 495-514.

Ball, S., Eckel, C., Grossman, P. and Zame, W. (2001), "Status in Markets”, Quarterly Journal of Economics, 116: 161-188.

Basil, D., Ridgway, N., Basil, M. (2001), "Guilt Appeals: The Effects of Responsibility and Altruistic Norms", Advances in Consumer Research, 28: 216.

Bénabou, R. and Tirole, J. (2006), "Incentives and Prosocial Behavior", American Economic Review, 96: 1652-1678.

Bergstrom, T., Blume, L. and Varian, H. (1986), "On the Private Provision of Public Goods", Journal of Public Economics, 29: 25-49.

Boadway, R., Pestieau, P. and Wildasin, D. (1989), "Tax-Transfer Policies and the Voluntary Provision of Public Goods", Journal of Public Economics, 39: 157-176.

Brubaker, E. (1975), "Free Ride, Free Revelation, or Golden Rule?", Journal of Law and Economics, 18: 147-161.

Bulow, J., Geanakoplos, J. and Klemperer, P. (1985), "Multimarket Oligopoly: Strategic Substitutes and Complements", Journal of Political Economy, 93: 488-511.

Chan, K, Mestelman, S., Moir, R. and Muller, A. (1996), "The Voluntary Provision of Public Goods under Varying Income Distributions", Canadian Journal of Economics, 96: 54-69.

Gilbert, M. (1997), "Group Wrongs and Guilt Feelings”, Journal of Ethics, 1: 65-84. 
Goethals, G. (1986), "Social Comparison Theory: Psychology from the Lost and Found", Personality and Social Psychology Bulletin, 12: 261-278.

House of Commons (2007), "The Voluntary Carbon Offset Market", Sixth Report of Session 2006-07, The Stationery Office Limited.

Hawkes, K., Altman, J., Beckerman, S., Grinker, R., Harpending, H., Jeske, R., Peterson, N., Smith, E., Wenzel, G. and Yellen, J. (1993), "Why Hunter-Gatherers Work: An Ancient Version of the Problem of Public Goods [and Comments and Reply]", Current Anthropology, 34: 341-361.

Hibbert, S., Smith, A., Davies, A. and Ireland, F. (2007), "Guilt Appeals: Persuasion Knowledge and Charitable Giving", Psychology and Marketing, 24: 723-742.

Holländer, H. (1990), “A Social Exchange Approach to Voluntary Cooperation”, American Economic Review, 80: 1157-1167.

Kolmar, M. and Wagener, A., (2008), "Contests and the Private Provision of Public Goods", University of St. Gallen Law and Economics Working Paper No. 2008-27.

Kotchen, M. (2009), “Offsetting Green Guilt”, Stanford Social Innovation Review, Spring 2009.

Kumru, C. and Vesterlund, L. (2008), "The Effect of Status on Voluntary Provision", Australian School of Business Research Paper No.2008 ECON 02.

Maurice, J., Rouaix, A. and Willinger, M. (2009), "Income Redistribution and Public Good Provision: an Experiment", LAMETA Working Paper 09-12.

Miceli, M. (1992), "How To Make Someone Feel Guilty: Strategies of Guilt Inducement and Their Goals", Journal for the Theory of Social Behavior, 22: 81-104.

Munoz-Garcia, F. (2009), "Competition for Status Acquisition in Public Good Games", Washington State University, School of Economic Sciences, WP 2008-12.

OCDE (2007), "L'économie politique des taxes liées à l'environnement", Les Synthèses de l'OCDE, available at: www.oecd.org/env/taxes

Olson, M. (1965), "The Logic of Collective Action: Public Goods and the Theory of Groups", Harvard University Press, First edition.

Podolny, J. (1993), “A Status-based Model of Market Competition”, American Journal of Sociology, 98: 829-872.

Regan, J. (1971), “Guilt, Perceived Injustice, and Altruistic BehaviorCompetitive altruism: From reciprocity to the handicap principle", Proceedings of the Royal Society of London B: Biological Sciences, 265: 427-431.

Roberts, G. (1998), "Competitive altruism: From reciprocity to the handicap principle", Proceedings of the Royal Society of London B: Biological Sciences, 265: 427-431.

Smith, E. and Bleige Bird, R. (2000), "Turtle Hunting and Tombstone Opening: Generosity as Costly Signaling", Evolution and Human Behavior, 21: 245-261.

Strahilevitz, M. and Myers, J. (1998), "Donations to Charity as Purchase Incentives: How Well They Work May Depend on What You are Trying to Sell", Journal of Consumer Research, 24: 434-446.

Warr, P. (1983), "The Private Provision of a Public Good is Independent of the Distribution of Income", Economics Letters, 13: 207-211. 


\section{Appendix}

\section{Proof of Proposition 1}

First, $\left(g_{i}^{*}, g_{j}^{*}\right)$ is a Nash equilibrium if and only if $g_{i}^{*}$ is a fixed point of the function: $x \rightarrow r_{i}\left(r_{j}\left(x, w_{j}\right), w_{i}\right)$ and $r_{j}\left(g_{i}^{*}\right)=g_{j}^{*}$. Second, if $\left(\partial r_{i} / \partial g_{j}\right) \in(-1,1)$ and $\left(\partial r_{j} / \partial g_{i}\right) \in(-1,1)$, $x \rightarrow r_{i}\left(r_{j}\left(x, w_{j}\right), w_{i}\right)$ has a unique fixed point and

$$
\frac{\partial r_{i}}{\partial g_{j}}=\frac{d H_{i} / d g_{j}}{-d H_{i} / d g_{i}}, \frac{\partial r_{j}}{\partial g_{i}}=\frac{d H_{j} / d g_{i}}{-d H_{j} / d g_{j}}
$$

\section{Proof of Proposition 2}

Consider the ratio which measures the relative incentives to contribute to the public good

$$
\gamma_{i}=\frac{d H_{i} / d x_{i}}{\left(d H_{i} / d g_{j}\right)-\left(d H_{i} / d g_{i}\right)}=\frac{\partial H_{i} / \partial x_{i}}{\left[\left(\partial H_{i} / \partial G\right)-\left(\partial H_{i} / \partial s_{i}\right)\right]-\left[\left(\partial H_{i} / \partial G\right)+\left(\partial H_{i} / \partial s_{i}\right)-\left(\partial H_{i} / \partial x_{i}\right)\right]}
$$

First of all, it is worth writing $\gamma_{i}$ according to the partial derivative of the reaction function $r_{i}$

$$
\gamma_{i}=\frac{\partial H_{i} / \partial x_{i}}{\left(\partial H_{i} / \partial x_{i}\right)-\left(2 \partial H_{i} / \partial s_{i}\right)}=\frac{\partial H_{i} / \partial x_{i}}{\left(\partial H_{i} / \partial g_{j}\right)-\left(\partial H_{i} / \partial g_{i}\right)}=\frac{\partial r_{i} / \partial w_{i}}{1+\left(\partial r_{i} / \partial g_{j}\right)}
$$

The income transfer corresponds to $d w_{i}=-d w_{j}>0$. At the unique equilibrium $G^{*}\left(w_{i}, w_{j}\right)$, agent $i$ 's provision satisfies $r_{i}\left(g_{j}^{*}, w_{i}\right)=g_{i}^{*}$ and differentiation of this relation gives

$$
d g_{i}^{*}=\frac{\partial r_{i}}{\partial g_{j}} d g_{j}^{*}+\frac{\partial r_{i}}{\partial w_{i}} d w_{i}
$$

Since $d g_{j}^{*}=d G^{*}-d g_{i}^{*}$, we have $d g_{i}^{*}=\left(\partial r_{i} / \partial g_{j}\right)\left(d G^{*}-d g_{i}^{*}\right)+\left(\partial r_{i} / \partial w_{i}\right) d w_{i}$. That is

$$
d g_{i}^{*}=\frac{\partial r_{i} / \partial g_{j}}{1+\left(\partial r_{i} / \partial g_{j}\right)} d G^{*}+\frac{\left(\partial r_{i} / \partial w_{i}\right)}{1+\left(\partial r_{i} / \partial g_{j}\right)} d w_{i}=\frac{\left(\partial r_{i} / \partial g_{j}\right)}{1+\left(\partial r_{i} / \partial g_{j}\right)} d G^{*}+\gamma_{i} d w_{i}
$$


A similar expression holds for $d g_{j}^{*}$ and summing both expressions gives

$$
\left[1-\frac{\left(\partial r_{i} / \partial g_{j}\right)}{1+\left(\partial r_{i} / \partial g_{j}\right)}-\frac{\left(\partial r_{j} / \partial g_{i}\right)}{1+\left(\partial r_{j} / \partial g_{i}\right)}\right] d G^{*}=\gamma_{i} d w_{i}+\gamma_{j} d w_{j}=\left(\gamma_{i}-\gamma_{j}\right) d w_{i}
$$

Because of (11), the first factor of the left hand side is positive thus

$$
d G^{*}>0 \Leftrightarrow \gamma_{i}>\gamma_{j}
$$

\section{Proof of Corollary 1}

Given $g_{j}$, differentiating $u(\cdot)$ with respect to $g_{i}$ gives best-response $g_{i}^{*}$. At an interior solution the first order condition is satisfied

$$
-\frac{1}{w_{i}-r_{i}}+\frac{\alpha_{i}+\beta_{i}}{\alpha_{i}\left(r_{i}+g_{j}\right)+\beta_{i}\left(r_{i}-g_{j}\right)}=0
$$

Therefore, $\left(\alpha_{i}+\beta_{i}\right)\left(w_{i}-r_{i}\right)=\alpha_{i}\left(r_{i}+g_{j}\right)+\beta_{i}\left(r_{i}-g_{j}\right)$, and

$$
r_{i}\left(g_{j}, w_{i}\right)=\frac{1}{2} w_{i}-\frac{1}{2} \frac{\left(\beta_{i}-\alpha_{i}\right)}{\left(\beta_{i}+\alpha_{i}\right)} g_{j}=\frac{1}{2} w_{i}-\frac{1}{2} A_{i} g_{j}
$$

This equation holds if the right hand side is between 0 and $w_{i}$ which is the case if $g_{j} \leq w_{i} / A_{i}$ when $A_{i}>0$ (i.e. $\alpha_{i}>\beta_{i}$ ) and $g_{j} \leq-w_{i} / A_{i}$ when $A_{i}<0$ (i.e. $\alpha_{i}<\beta_{i}$ ). When $\left(\beta_{i}-\alpha_{i}\right)=0$, $r_{i}=(1 / 2) w_{i}$ for any $g_{j} \geq 0$. The same reasoning applies to agent $j$.

\section{Proof of Corollary 2}

At an interior equilibrium, the two following equations are satisfied

$$
\left\{\begin{array}{l}
2 g_{i}^{*}+A_{i} g_{j}^{*}=w_{i} \\
A_{j} g_{i}^{*}+2 g_{j}^{*}=w_{j}
\end{array}\right.
$$




$$
\text { where } A_{i}=\frac{\alpha_{i}-\beta_{i}}{\alpha_{i}+\beta_{i}}, A_{j}=\frac{\alpha_{j}-\beta_{j}}{\beta_{j}+\alpha_{j}} \in(-1,1) \text {. }
$$

The aggregation of provisions amounts to

$$
\left[\begin{array}{l}
g_{i} \\
g_{j}
\end{array}\right]=\frac{1}{4-A_{i} A_{j}}\left[\begin{array}{cc}
2 & -A_{i} \\
-A_{j} & 2
\end{array}\right]\left[\begin{array}{l}
w_{i} \\
w_{j}
\end{array}\right]=\frac{1}{4-A_{i} A_{j}}\left[\begin{array}{l}
2 w_{i}-A_{1} w_{j} \\
2 w_{j}-A_{2} w_{i}
\end{array}\right]
$$

and the total provision is

$$
G^{*}=\frac{1}{4-A_{i} A_{j}}\left[\left(2-A_{j}\right) w_{i}+\left(2-A_{i}\right) w_{j}\right]
$$

When $\beta_{i}=\beta_{j}=0$ and agents are exclusively intrinsically impulsed

$$
G^{*}=\frac{2 w_{i}-w_{i}+2 w_{j}-w_{j}}{4-1}=\frac{1}{3}\left(w_{i}+w_{j}\right)
$$

\section{Proof of Corollary 4}

$$
\begin{gathered}
\ln \left(w_{i}-y_{i}\right)+\ln \left[\alpha_{i}\left(y_{i}+y_{j}\right)+\frac{1}{1-\sigma} \beta_{i}\left(y_{i}-y_{j}\right)\right] \\
-\frac{1}{w_{i}-y_{i}}+\frac{\alpha_{i}+\left(\beta_{i} / 1-\sigma\right)}{\alpha_{i}\left(y_{i}+y_{j}\right)+\beta_{i}\left(y_{i}-y_{j} / 1-\sigma\right)}=0 \\
\left(w_{i}-y_{i}\right)\left[\alpha_{i}+\left(\beta_{i} / 1-\sigma\right)\right]=\alpha_{i}\left(y_{i}+y_{j}\right)+\beta_{i}\left(y_{i}-y_{j} / 1-\sigma\right) \\
y_{i}^{*}=w_{i}-y_{j} \frac{\alpha_{i}-\beta_{i}(1 / 1-\sigma)}{\alpha_{i}+\beta_{i}(1 / 1-\sigma)}
\end{gathered}
$$

At an interior equilibrium, the two following equations are satisfied

$$
\left\{\begin{array}{l}
y_{i}^{*}+B_{i} y_{j}^{*}=w_{i} \\
B_{j} y_{i}^{*}+y_{j}^{*}=w_{j}
\end{array}\right.
$$

where $B_{i}=\frac{\alpha_{i}-\beta_{i}(1 / 1-\sigma)}{\alpha_{i}+\beta_{i}(1 / 1-\sigma)}, B_{j}=\frac{\alpha_{j}-\beta_{j}(1 / 1-\sigma)}{\alpha_{j}+\beta_{j}(1 / 1-\sigma)}$. 
The aggregation of joint supplies amounts to

$$
\left[\begin{array}{l}
y_{i} \\
y_{j}
\end{array}\right]=\frac{1}{1-B_{i} B_{j}}\left[\begin{array}{cc}
1 & -B_{i} \\
-B_{j} & 1
\end{array}\right]\left[\begin{array}{c}
w_{i} \\
w_{j}
\end{array}\right]=\frac{1}{1-B_{i} B_{j}}\left[\begin{array}{c}
w_{i}-B_{1} w_{j} \\
w_{j}-B_{2} w_{i}
\end{array}\right]
$$

and the total provision is

$$
Y^{*}=\frac{1}{1-B_{i} B_{j}}\left[\left(1-B_{j}\right) w_{i}+\left(1-B_{i}\right) w_{j}\right]
$$

Subsidizing decreases $B_{i}$ and $B_{j}$, and by Corollary 2, it increases the aggregate joint supply of the public good.

\section{Proof of Corollary 5}

With symmetric agents and dissimilar incomes, first order conditions are

$$
\left[\begin{array}{ll}
1 & B \\
B & 1
\end{array}\right]\left[\begin{array}{l}
\partial y_{i} / \partial \sigma \\
\partial y_{j} / \partial \sigma
\end{array}\right]=-\frac{\partial B}{\partial \sigma}\left[\begin{array}{l}
y_{i} \\
y_{j}
\end{array}\right]
$$

Thus

$$
\left[\begin{array}{l}
\partial y_{i} / \partial \sigma \\
\partial y_{j} / \partial \sigma
\end{array}\right]=-\frac{1}{\Delta} \frac{\partial B}{\partial \sigma}\left[\begin{array}{l}
y_{i}-B y_{i} \\
y_{j}-B y_{j}
\end{array}\right]
$$

From which we obtain

$$
y_{j}-B y_{j}=\frac{1}{\Delta}\left[1\left(w_{j}-B w_{i}\right)-B\left(w_{i}-B w_{j}\right)\right]
$$

The right hand side is negative if and only if $B>0$ and $w_{i}>\frac{2+B^{2}}{B} w_{j}$. 